\title{
DETERMINANTS OF CAPITAL STRUCTURE OF SMALL AND MEDIUM ENTERPRISE IN PORTUGAL AND SPAIN
}

\author{
David Cabaço, University of Évora, Évora, Portugal \\ Margarida Saraiva, University of Évora and BRU-UNIDE/ISCTE-IUL, Évora, Portugal \\ José Correia, University of Évora, Évora, Portugal \\ Jorge Casas Novas, University of Évora and CEFAGE-UE, Évora, Portugal
}

\begin{abstract}
The main objective of this article is to analyze the determinants of the capital structure of small and medium enterprises (SME's) using a sample of companies in Portugal and Spain and a multiple linear regression with panel data for the period between 2005 and 2008. The explanatory variables of the dependent variable capital structure are dimension, growth opportunities, asset tangibility, profitability, and profit rate. The results show that SME's in both countries are similar in the choice of capital structure. The determinant "profit rate" was not relevant to explain the level of indebtedness of SME's. The indicators growth opportunities, profitability and asset tangibility considered in the analysis shown to be determinants on the capital structure of the companies under analysis. Finally, the indicator "dimension" is significant for Portugal but not for Spain.
\end{abstract}

Keywords: Capital structure, Determinant factors, Panel data, Indebtedness. 